\title{
Airway responsiveness, respiratory symptoms, and exposures to soluble oil mist in mechanical workers
}

\author{
N Massin, A B Bohadana, P Wild, P Goutet, H Kirstetter, J P Toamain
}

\begin{abstract}
Objectives-To assess the relation between measured levels of exposure to soluble oil mists in a plant manufacturing ball bearings, and both respiratory symptoms and airway responsiveness in the workforce.

Methods-114 male workers exposed to oil mist and 55 unexposed male controls from nearby factories were studied. Soluble oil mist concentrations were measured with area samplers. Respiratory symptoms were assessed by questionnaire and measurement of airway responsiveness to methacholine with an abbreviated method. Subjects were labelled positive to methacholine airway challenge (MAC+) if forced expiratory volume in one second $\left(F_{1}\right)_{1}$ fell by $\geqslant 20 \%$. The linear doseresponse slope was calculated as the percentage fall in $F_{1}$ at the last dose divided by the total dose given.
\end{abstract}

Results-Geometric mean concentrations of oil mists ranged from $0.65 \mathrm{mg} / \mathrm{m}^{3}$ (GSD 1.29 ) to $2.20 \mathrm{mg} / \mathrm{m}^{3}$ (GSD 1.55 ) based on 92 measurements obtained from 1979-93. The prevalence of chronic cough or phlegm, bouts of bronchitis, and dyspnoea was greater among exposed workers than among controls (odds ratio (OR) $4.64, P=0.002$ for chronic cough and phlegm). After adjustment for smoking and age, dyspnoea was significantly related to an index of cumulative exposure to oil mist $(O R 1.44, P=0.006 / 10$ $\left.\mathrm{y} \cdot \mathrm{mg} / \mathrm{m}^{3}\right)$. The proportion of $\mathrm{MAC}+$ subjects was similar in the two groups. However, after adjustment for baseline FEV $_{1}$ and age, the dose-response slope was significantly steeper among exposed workers than among controls $(P=0.01)$, a finding indicating airway hyperresponsiveness in the exposed workers. Furthermore, the dose-response slope was significantly related to baseline $F_{E V}$, age, and, after adjustment for $F E V_{1}$, the index of cumulative exposure to oil $(P=$ 0.004).

Conclusion-Subjects with exposure to soluble oil mist in the metal industry are at risk of developing both respiratory symptoms and airway hyperresponsiveness.

(Occup Environ Med 1996;53:748-752)

Keywords: airway responsiveness; respiratory symptoms; soluble mineral oils
Worldwide, several million workers are regularly exposed to mists of machining fluids in the metal industry. These fluids are complex mixtures of oil (mineral or synthetic) and other substances-for example, water, emulsifiers, corrosion inhibitors, bactericides, etcwhich are used mainly as lubricants and coolers to prevent the welding of the metal parts to the cutting tool itself. Previous investigations have shown adverse respiratory effects of occupational exposure to oil mists: epidemiological studies showed that workers exposed to various types of mineral oil mists were more likely to have increased rates of symptoms of chronic bronchitis than control subjects. ${ }^{12}$ Also, several patients exposed to oil mists had occupational asthma and were referred to a respiratory clinic because of asthmatic symptoms. ${ }^{34}$ Finally, a recent report showed a significant decline in forced expiratory volume in one second $\left(\mathrm{FEV}_{1}\right)$ during shifts among nonasthmatic machine operators exposed to relatively low concentrations of mists of machining fluids in the metal industry. ${ }^{5}$

Over the past two decades, the proportion of oil in the composition of machining fluids fell drastically from $100 \%$ in straight cutting oils to $\leqslant 10 \%$ nowadays in soluble mineral oils. In this study we consider the question of the relation between levels of exposure to soluble oil mists and respiratory symptoms and indices of airway responsiveness to methacholine, a matter on which there is only limited information. The results were compared with those obtained in a group of unexposed control subjects.

\section{Materials and methods}

\section{STUDY DESIGN AND SUBJECTS}

A cross sectional survey of 114 male employees was carried out, representing $85 \%$ of the workforce at a plant manufacturing ball bearings in eastern France which has used only soluble mineral oil over the past 25 years. All workers have been chronically exposed to mists of soluble mineral oils for at least one year. The control population was a group of 55 blue collar male workers who had never been at occupational risk of exposure to mineral oils or any other respiratory hazard. They represented $90 \cdot 2 \%$ of the workforce $(n=61)$ at two manufacturing plants: a food distribution plant $(n=27)$ and a stationery factory $(n=28)$. They were from the same geographical region and worked the same shifts as the exposed workers; both groups were examined in the autumn of 1993 . Written and informed 
consent was given by all subjects. Information was obtained about age, working hours a day, long term duration of work, and occupational history. Table 1 shows the prestudy characteristics of exposed workers and controls.

\section{EXPOSURE MONITORING}

The current concentrations of soluble mineral oils in the workplaces were measured over periods of two to three hours with area samplers. Ambient air was aspirated through glass fibre filter paper (GF/C Whatman, $37 \mathrm{~mm}$ in diameter) with small vacuum pumps (Dupont S-2500, Kennett Square, PA, USA) the flow rate of which was kept at $1.01 / \mathrm{min}$. The oil was extracted from the filter with dichloromethane and its concentration was determined by gravimetric analysis. ${ }^{6}$ Repeated samples were obtained from 1979 to 1993 to take changes in the working conditions into account. It has to be stressed that this methodology was developed to assess straight cutting oils consisting mainly of mineral oil. In fact, the values measured in this study can only be considered as an indicator of the exposure as $<10 \%$ of the mist is soluble in dichloromethane.

For a given area, the concentration of oil mist was calculated as the geometric mean value of the measurements obtained in that area: the figures were rounded to the nearest whole number to provide a score which was assigned individually to all workers in the area. Next, for a given worker, the exposure score was multiplied by the number of working months in the area for the period of employment as a whole. This allowed for the calculation of an index of estimated exposure to oil mist-namely, the cumulative exposure to oil.

\section{RESPIRATORY HEALTH STATUS \\ Medical history}

Detailed histories of respiratory diseases and smoking habits were recorded. All subjects completed a modified version of the European Coal and Steel Community questionnaire on respiratory symptoms ${ }^{7}$ which was given by the same experienced interviewer. ${ }^{89}$ The questionnaire emphasised the past and present personal and family histories of cough, phlegm, or both, asthma, wheeze, and dyspnoea. Chronic bronchitis was defined as cough and phlegm for at least three months each year for not less than two successive years. The term chronic cough or phlegm was

Table 1 Anthropometric characteristics, smoking history, and duration of exposure in workers exposed to soluble mineral oil mists and controls

\begin{tabular}{lcc}
\hline & $\begin{array}{l}\text { Exposed workers } \\
(n=114)\end{array}$ & $\begin{array}{c}\text { Controls } \\
(n=55)\end{array}$ \\
\hline Age (mean (SD), y) & $38(9)$ & $30(8)$ \\
Weight (mean (SD), kg) & $81(12)$ & $73(10)$ \\
Height (mean (SD), cm) & $176(8)$ & $174(6)$ \\
Smoking status: & $47(41)$ & $37(67)$ \\
$\quad$ Current smokers (n (\%)) & $41(36)$ & 0 \\
$\quad$ Ex-smokers (n (\%)) & $26(23)$ & $18(33)$ \\
Never smokers (n) (\%)) & $12(9)$ & $9(7)$ \\
Smokers (mean (SD), pack-years) & $12(11)$ & - \\
Ex-smokers (mean (SD), pack-years) & $15(8)$ & - \\
Duration of exposure (mean (SD), y) & 15 \\
\hline
\end{tabular}

used to define subjects complaining of cough, or phlegm, or both regardless of duration: thus it encompassed those subjects who fulfilled the criteria for chronic bronchitis and those who did not. Bouts of bronchitis was the term coined to define those subjects who answered yes to the question: "Have you ever experienced an increase in the severity of cough and in the volume of sputum production of at least three weeks in duration during the past three years?" Dyspnoea on exertion was considered to be present when the subjects complained of breathlessness when walking up a slight hill. Asthma was considered to be present if the subjects answered yes to the question: "Have you ever been diagnosed as having bronchial asthma?".

Non-smokers were defined as subjects who had never regularly smoked one or more cigarettes a day or had smoked one or more cigarettes a day for less than one year. Current smokers were defined as subjects who reported regular smoking of one or more cigarettes a day for at least one year. Ex-smokers were subjects who reported smoking one or more cigarettes regularly in the past but who had stopped smoking at least one year before the study.

\section{Pulmonary function tests}

Spirometry was carried out by the same experienced technician (JPT) with an electronic thermister spirometer (Spiro-Analyzer ST 300, Fukuda Sangyo, Tokyo, Japan). The following indices were obtained by having the subject expire forcefully and maximally after a maximal inspiratory manoeuvre: forced vital capacity (FVC), forced expiratory volume in one second $\left(\mathrm{FEV}_{1}\right)$, forced expiratory flow between 25 and $75 \%$ of the FVC $\left(\mathrm{FEF}_{25-75}\right)$, and maximal expiratory flows at $25 \%$, and $50 \%$ of the FVC $\left(\operatorname{Vmax}_{25}, \operatorname{Vmax}_{50}\right.$, respectively). At baseline each subject performed at least three reproducible forced expiratory manoeuvres (within $5 \%$ for FVC and $\mathrm{FEV}_{1}$ ); thereafter only two reproducible curves were required. The curve with the highest sum of $\mathrm{FVC}+\mathrm{FEV}_{1}$ was used for statistical analysis. ${ }^{10}$ The results were expressed as standardised residuals (SR) ( $S R=$ (observed value-predicted value)/residual standard deviation (RSD)) as recommended by a committee of the European Community for Steel and Coal. ${ }^{11}$ An SR of zero indicates that the observed value is equal to the control value (at the 50 th percentile); SRs of -1.64 or 1.96 indicate that the results are at the 5 th percentile and the $97 \cdot 5$ th percentile respectively.

\section{Airway responsiveness}

As the examinations were carried out during workshifts, an abbreviated version of the methacholine airway challenge (MAC) test was used. ${ }^{12} 13$ Three cumulative doses of methacholine $(0.5 \mu \mathrm{mol}, 2.5 \mu \mathrm{mol}, \quad$ and $7.5 \mu \mathrm{mol}$-that is, $100 \mu \mathrm{g}, 500 \mu \mathrm{g}$, and $1500 \mu \mathrm{g}$ respectively) were given with a nebuliser (Mediprom FDC 88-Paris, France) delivering doses of $0.5 \mu \mathrm{mol}$ methacholine per breath. A noseclip was worn and the aerosol 
Table 2 Prevalence of respiratory symptoms in workers exposed to soluble mineral oil mists and controls

\begin{tabular}{|c|c|c|c|c|}
\hline Symptoms & $\begin{array}{l}\text { Exposed } \\
\text { workers } \\
(n=114)\end{array}$ & $\begin{array}{l}\text { Controls } \\
(n=55)\end{array}$ & OR & $P$ value \\
\hline Chronic bronchitis (n (\%)) & $9(8)$ & $1(2)$ & - & - \\
\hline Chronic cough or phlegm (n (\%)) & $36(32)$ & $6(11)$ & $4.90 \dagger$ & 0.002 \\
\hline Bouts of bronchitis (n (\%)) & $19(17)$ & $1(2)$ & & \\
\hline Dyspnoea (n (\%)) & $30(28)$ & $6(11)$ & $\begin{array}{l}2 \cdot 28 \ddagger \\
1.44 \llbracket / 10 y\end{array}$ & $\begin{array}{l}0 \cdot 10 \\
0 \cdot 006\end{array}$ \\
\hline Asthma (n (\%)) & $6(5)$ & $2(4)$ & - & - \\
\hline
\end{tabular}

${ }^{\star}$ Based on the standardised coefficient in the multiple logistic regression.

†Exposed $v$ control adjusted for smoking consumption (pack-years) and age in a multiple logistic regression.

Exposed $v$ control adjusted for age and smoking in a multiple logistic regression.

SOR by cumulative exposure $\left(/ 10 \mathrm{y} \cdot \mathrm{mg} / \mathrm{m}^{3}\right)$ adjusted for age and smoking.

inhaled through the mouth slowly. Then the breath was held for five seconds. Spirometry was performed in the sitting position, before and three minutes after the inhalations of methacholine. The challenge test was discontinued either after the inhalation of the third dose of methacholine or if the $\mathrm{FEV}_{1}$ fell by $\geqslant 20 \%$ below the baseline value.

Subjects who experienced a fall in $\mathrm{FEV}_{1}$ of $\geqslant 20 \%$ were classified as having a positive MAC test (MAC+) - that is, the airway was hyperresponsive. A linear dose-response slope was calculated by the method proposed by $\mathrm{O}^{\prime}$ Connor and colleagues ${ }^{13}$ as the percentage fall in $\mathrm{FEV}_{1}$ at the last dose divided by the total dose of methacholine given.

ETHICS

The study was approved by the local medical ethics committee.

\section{STATISTICAL ANALYSIS}

To be able to apply a multivariate analysis to the dose-response slope, a transformation to normalise the data was applied. The transformation $1 /($ slope $+2 \cdot 5)$ in the family of shifted logarithmic and shifted inverse transformations was found to be optimal for a large unexposed population. ${ }^{8}$

Statistical analysis was carried out with the SAS statistical software. ${ }^{14}$ Multiple logistic regression analyses were used to assess the effect of the exposure on the symptoms while adjusting for smoking status and age (for dyspnoea).

Multiple linear regression was used to describe the effect of exposure on the baseline spirometric variables (expressed as SRs) adjusted on tobacco consumption, and on the transformed dose-response slope adjusted for baseline $\mathrm{FEV}_{1}$ and age. We did not include

Table 3 Baseline pulmonary function variables (mean standardised residuals (SD)) in workers exposed to soluble mineral oil mists and controls

\begin{tabular}{|c|c|c|c|}
\hline Variable & $\begin{array}{l}\text { Exposed workers } \\
(n=114)\end{array}$ & $\begin{array}{l}\text { Controls } \\
(n=55)\end{array}$ & Pvalue ${ }^{\star}$ \\
\hline $\begin{array}{l}\text { FVC } \\
\text { FEV }_{1} \\
\text { FVC/FEV }_{1} \\
\text { FEF }_{25} 75 \\
{\text { V } \max _{50}} \\
\text { V } \max _{25}\end{array}$ & $\begin{array}{r}0.37(0.92) \\
0.38(1.08) \\
0.20(0.79) \\
-0.13(1.11) \\
0.10(1.28) \\
-0.45(0.94)\end{array}$ & $\begin{array}{r}0.47(0.91) \\
0.22(0.98) \\
0.14(0.78) \\
-0.26(0.95) \\
0.04(1.04) \\
-0.40(0.84)\end{array}$ & $\begin{array}{l}0.14 \\
0.06 \\
0.30 \\
0.11 \\
0.24 \\
0.54\end{array}$ \\
\hline
\end{tabular}

^Significance in general linear model adjusted for tobacco consumption.

$\mathrm{FVC}=$ forced expiratory vital capacity $; \mathrm{FEV}_{1}=$ forced expiratory volume in one second $\mathrm{FEF}_{25.75}=$ forced expiratory flow between $25 \%$ and $75 \%$ of the FVC; V $\max _{50}=\operatorname{maximal}_{\text {expira }}$ tory flow at $50 \%$ of the expired FVC; $V \max _{25}=$ forced expiratory flow at $25 \%$ of the expired
FVC. smoking in this model as we found that this variable was unrelated to bronchial responsiveness. The stability of the variance and approximate linearities in the linear models were checked on residual plots.

\section{Results}

\section{EXPOSURE ASSESSMENT}

Overall, 92 samplings were performed: 20 in the cutting area and 72 in the machining area. In the cutting area, the geometric mean concentration of measurements carried out in 1989 was 1.49 (GSD 1.22$) \mathrm{mg} / \mathrm{m}^{3}$; as no major hygiene measures aimed at improving the air quality were carried out in this area between 1979 and 1993, this value was considered to be representative of the working conditions in this period. In the machining area, the geometric mean concentration value of 46 samplings performed between 1979 and 1989 was $2 \cdot 20($ GSD 1.55$) \mathrm{mg} / \mathrm{m}^{3}$. After hygiene measures aimed at improving ventilation were adopted in 1990, the geometric mean value of 26 measurements decreased to 0.65 (GSD 1.29) $\mathrm{mg} / \mathrm{m}^{3}$. Both these mean values were taken into account in the exposure assessment of subjects working in this area.

RESPIRATORY SYMPTOMS AND BASELINE LEVEL OF PULMONARY FUNCTION

Overall, the prevalence of respiratory symptoms tended to be greater among the exposed workers than among unexposed controls. The proportion of subjects with chronic bronchitis, chronic cough or phlegm, or bouts of bronchitis was three to nine times as great among workers exposed to oil mist than in unexposed controls; for chronic cough or phlegm the differences were significant (table 2). After adjustment for smoking and age (on average exposed workers were eight years older than controls), dyspnoea seemed to be significantly related to the index of cumulative exposure to oil mist, but for asthma the differences were not significant (table 2). It is interesting to notice, however, that five out of six exposed workers developed asthma after they were hired, whereas both controls with asthma had had it since childhood: in one asthma persisted through adult life and in the other it had disappeared by the age of 11 .

After adjustment for tobacco consumption, workers exposed to oil mist had baseline pulmonary function variables similar to those of unexposed controls (table 3). After adjustment for tobacco consumption, baseline $\mathrm{FEV}_{1}$ was not related to oil exposure.

\section{AIRWAY RESPONSIVENESS}

The methacholine airway challenge test was carried out in all exposed workers $(n=114)$ and unexposed controls $(n=55)$. A positive MAC test (MAC+ $=\mathrm{FEV}_{1}$ fall $\geqslant 20 \%$ ) was found in 14 out of the 169 subjects tested; the proportion in exposed workers was similar to that in controls (table 4).

In contrast, mean dose-response slope values were significantly lower (steeper slope) in 
Table 4 Airway responsiveness to methacholine among workers exposed to soluble mineral oil mists and controls

\begin{tabular}{llll}
\hline & $\begin{array}{l}\text { Exposed workers } \\
(n=114)\end{array}$ & $\begin{array}{l}\text { Controls } \\
(n=55)\end{array}$ & P value \\
\hline $\begin{array}{l}\text { MAC }+(\mathrm{n}(\%)) \\
(1 /(\text { slope }+2.5))(\text { mean }(\mathrm{SD}))\end{array}$ & $10(9)$ & $4(8)$ & $>0.5^{\star}$ \\
\hline
\end{tabular}

$\chi^{2}$ test.

tBased on a linear model after adjusting for baseline $\mathrm{FEV}_{1}$ and age.

MAC $+=$ positive spirometric methacholine airway challenge (\% fall in $\mathrm{FEV}_{1}$ by $\geqslant 20 \%$ ); dose-response slope $=\left(\right.$ slope $=\%$ fall in $\mathrm{FEV}_{1} / \mathrm{mmol}$ methacholine $)$.

Table 5 Multiple regression of the dose-response slope $e^{\star}$ on baseline $F E V_{1}$, age, and exposure to soluble oil mists expressed in terms of cumulative exposure

\begin{tabular}{lcll}
\hline Factor & Coefficient & $S E$ & P value \\
\hline Constant & 0.05256 & & \\
Baseline FEV $1(1)$ & 0.04269 & 0.0086 & 0.0001 \\
Age (y) & 0.00195 & 0.0008 & 0.029 \\
Cumulative exposure $\left(10 \mathrm{y} \cdot \mathrm{mg} / \mathrm{m}^{3}\right)$ & -0.0099 & 0.0003 & 0.004 \\
\hline
\end{tabular}

$\star$ Dose-response slope $=1 /\left(\%\right.$ fall in $\left.\mathrm{FEV}_{1} / \mathrm{mmol}+2 \cdot 5\right)$.

workers exposed to oil than in controls, a finding indicating overall airway hyperresponsiveness in the exposed group (table 4).

Multiple regression analysis was used to assess the relative contribution of measured variables to dose-response slope values. The only variables likely to influence dose-response slope values were baseline $\mathrm{FEV}_{1}$, age, and exposure to soluble oil mist. Table 5 shows the significance of the values included in this model for the group as a whole. From this model it can be seen that 10 years of exposure at $1 \mathrm{mg} / \mathrm{m}^{3}$ is modelled to have the same effect on dose-response slope as a $230 \mathrm{ml}$ decrease in the baseline $\mathrm{FEV}_{1}$.

\section{Discussion}

This study shows that workers exposed to soluble mineral oil mist have more respiratory symptoms and are significantly more hyperresponsive to methacholine than are comparable unexposed controls.

To the best of our knowledge, the recent paper by Ameille and colleagues ${ }^{15}$ is the only investigation published in English dealing with airway responsiveness to methacholine in workers exposed to soluble oil mist. These authors examined the prevalence of respiratory symptoms, ventilatory abnormalities, and airway hyperresponsiveness in workers exposed to mists of straight cutting oil $(n=40)$, soluble mineral oil $(n=51)$, or a mixture of straight cutting oil and soluble mineral oil $(n=139)$, and compared the results with those found in a group of unexposed controls $(n=78)$. Overall, only slight adverse effects on respiratory symptoms and lung function were found which were restricted to workers exposed to straight cutting oil. Moreover, no effect of exposure was found on airway responsiveness, whatever group was considered.

Theoretically, the differences in the degree of airway responsiveness of our workers compared with those exposed to soluble mineral oil in the study of Ameille and colleagues ${ }^{15}$ could be explained by various factors including the exposure, the challenge test, or both. It is unlikely that exposure was the only factor involved as the type of oil used as well as the mean duration of exposure were similar in the two studies. Differences related to the technique of giving the methacholine can also be discarded confidently as, in both studies, similar doses of this agent were given through identical nebulisers, and the test results were expressed with similar indices.

A more likely source of disagreement lies in the way of calculating the dose-response slope: indeed, whereas we added a constant of +2.5 (see methods section) to our slopes to achieve a distribution as close to normal as possible, Ameille and colleagues chose to omit negative slopes. ${ }^{15}$ However, when they reanalysed their data (for workers exposed to soluble oil mist) with our methods, their results became similar to ours (P Wild, personal communication).

The significance of non-specific airway hyperresponsiveness in occupational samples in general is not completely understood. In other types of occupational exposure airway hyperresponsiveness is often associated with respiratory symptoms and impaired lung function. ${ }^{16}$ Although such cross sectional associations do not indicate whether airway hyperresponsiveness itself is a risk factor that precedes the development of these abnormalities or not, their documentation is important for they provide the rationale for longitudinal studies necessary to answer this question. In this study we show that workers exposed to oil mist present airway hyperresponsiveness to methacholine which is significantly related to an index of cumulative exposure to oil. We also showed that these workers have significantly increased rates of chronic cough or phlegm and dyspnoea. Dyspnoea was related to an index of cumulative exposure to oil mist. In our opinion, although these associations do not constitute formal evidence of a causal relation they surely provide a strong argument pointing in that direction.

Considering the current concept on the mechanisms of non-specific airway hyperresponsiveness ${ }^{17}$ we are tempted to suggest that in our workers this resulted from airway inflammation due to longstanding exposure to oil mist. Theoretically, such inflammation might have resulted either from airway sensitisation to specific components of oil mists or to a non-specific irritant airway effect, or both. Indeed, the sensitisation to specific components of oil mists has been documented in cases of occupational asthma ${ }^{34}$ whereas the non-specific irritant airway effect has been used to explain acute lung response to sustained exposure to oil mist. ${ }^{5}$

This study is limited by the fact that the exact composition of the soluble mineral oil mists our workers were exposed to is unknown, thus preventing further consideration of the possible agent or agents likely to be involved in a theoretical inflammatory process. However, this by no means reduces the importance of the impairment in respiratory health that we found in workers exposed to soluble oil mist.

To summarise, this study shows that workers exposed to soluble oil mist have significantly 
more airway hyperresponsiveness to methacholine and chronic respiratory symptoms than unexposed controls. Careful controlled longitudinal studies are necessary to find whether or not this abnormality represents an early manifestation of occupational asthma or chronic airway obstruction.

1 Krzesniak L, Kowalski J, Droszcz W, Piotrowska Warsaw B. Respiratory abnormalities in workers exposed to oil mists. Eur ₹ Respir Dis 1981;62(suppl 113):88-9.

2 Jarvholm B, Bake B, Lavenius B, Thiringer G, Vokmann R. Respiratory symptoms and lung function in oil mistRespiratory symptoms and lung function in

3 Hendy MS, Beattie BE, Burge PS. Occupational asthma due to an emulsified oil mist. Br F Ind Med 1985;42:51-4. due to an emulsified oil mist. Br f Ind Med 1985;42:51-4.
Robertson AS, Weir DC, Sherwood Burge P. Occupational Robertson AS, Weir DC, Sherwood Burge P. Occupa
asthma due to oil mists. Thorax 1988;43:200-5.

5 Kennedy SM, Greaves IA, Kriebel D, Eisen EA, Smith TJ Woskie SR. Acute pulmonary responses among automobile workers exposed to aerosols of machining fluids. $A n$ F Ind Med 1989;15:627-41.

6 Institut National de Recherche et de Sécurité. Guide pratique de ventilation no 6-captage et traitement des brouillards d'huile entieres. Institut National de Recherche et de Sécurité 30, Rue Olivier Noyer, 75680 Paris Cedex 14 INRS: 1985. (INRS, Ed 680119.)

7 Minette A, Aresini G, Sanna-Randaccio F, Seaton A Smidt U, Teculescu D. Questionnaire de la CECA pour l'etude des symptomes respiratoires. 1987, $3 \mathrm{me}$ ed.

8 Bohadana AB, Massin N, Wild P, Kolopp M-N, Toamain
J-P. Respiratory symptoms and airway responsiveness in apparently healthy workers exposed to flour dust. Eur Respir 7 1995; 7:1070-6.

9 Massin N, Bohadana AB, Wild P, Kolopp-Sarda M-N, Toamain J-P. Airway responsiveness to methacholine, respiraory symptoms and dust exposure levels in grain and flour mill workers in Eastern France. $A m \mathcal{F}$ Ind $\mathrm{Med}$ 1995;27:859-69.

10 American Thoracic Society. Standardization of spirometry 1994 update. Am 7 Respir Crit Care Med 1995;152: $1107-36$

11 Quanjer PhH, Tammeling GJ, Cotes JE, Pedersen OF, Peslin R, Yernault JC. Lung volumes and forced respiratory flows. Report of the Working Party on Standardization of Lung Function Tests for the European Community for Coal and Steel. Eur Respir 7 1993;6(suppl 16):5-40.

12 Gardner RM. Report of snowbird workshop on standardisation of spirometry. Am Rev Respir Dis 1979;119:831-8.

13 O'Connor G, Sparrow D, Taylor D, Segal M, Weiss S. Analysis of dose-response curves to methacholine. An approach suitable for population studies. Am Rev Respir Dis 1987;138:1412-7.

14 SAS Institute. SAS/SAT user's guide, version 6, 4th ed, vol 2. Cary, NC: SAS Institute, 1989:846.

15 Ameille J, Wild P, Choudat D, Ohl G, Vaucouleur JF Chanut JC, et al. Respiratory symptoms, ventilatory impairment, and bronchial reactivity in oil mist-exposed workers. Am $f$ Ind Med 1995;27:247-56.

16 Lam S, Won R, Young M. Nonspecific bronchial reactivity in occupational asthma. $\mathcal{F}$ Allergy Clin Immunol 1979;

17 Hargreave FE, Dolovich J, O'Byrne PM, Ramsdale HE Daniel EE. The origin of airway hyperresponsiveness. $\mathscr{f}$ Allergy Clin Immunol 1986;78:825-32. 